\section{Commentary: Mechanical aortic graft injury after thoracoabdominal aortic aneurysm repair: A reminder that even the little details matter}

Andrew M. Vekstein, MD, Nicholas D. Andersen, MD, and G. Chad Hughes, MD

Open thoracoabdominal aortic aneurysm (TAAA) repair is a technically complex operation associated with a number of anatomic and mechanical complications. ${ }^{1}$ Notably, aortoesophageal fistula and diaphragmatic hernia represent examples of delayed anatomic complications after open TAAA repair. ${ }^{2,3}$ To facilitate exposure of the distal aortic arch for the proximal extent of repair, it is not uncommon to resect a posterior segment of rib four, five or six. ${ }^{4} \mathrm{Com}$ plications of this maneuver are rare but possible, particularly if an associated rib fracture is present. ${ }^{5}$

In this issue of JTCVS Techniques, Ishii and colleagues ${ }^{6}$ report a case of delayed aortic graft perforation due to puncture injury from a rib stump. A previous computed tomography scan revealed contact between the graft and the stump, which had been carefully "smoothed" intraoperatively. Despite emergent resuscitative efforts, the patient expired from anoxic brain injury. The authors submit a word of caution about any contact between TAAA graft material and potentially perilous anatomic remnants from the surgery, which may lead to a friction-based injury. They review some similar cases in the literature, in which graft injury occurred secondary to ribs, spinal body bone spurs,

From the Division of Cardiovascular and Thoracic Surgery, Department of Surgery, Duke University Medical Center, Durham, NC.

Disclosures: The authors reported no conflicts of interest.

The Journal policy requires editors and reviewers to disclose conflicts of interest and to decline handling or reviewing manuscripts for which they may have a conflict of interest. The editors and reviewers of this article have no conflicts of interest.

Received for publication April 13, 2021; revisions received April 13, 2021; accepted for publication April 22, 2021; available ahead of print April 27, 2021.

Address for reprints: Nicholas D. Andersen, MD, Division of Cardiovascular and Thoracic Surgery, Duke Children's Pediatric \& Congenital Heart Center, 2301 Erwin Rd, DUMC 3443, Durham, NC 27710 (E-mail: nicholas.andersen@ duke.edu). JTCVS Techniques 2021;8:44-5

2666-2507

Copyright (C) 2021 The Author(s). Published by Elsevier Inc. on behalf of The American Association for Thoracic Surgery. This is an open access article under the CC BY-NC-ND license (http://creativecommons.org/licenses/by-nc-nd/4.0/).

https://doi.org/10.1016/j.xjtc.2021.04.023

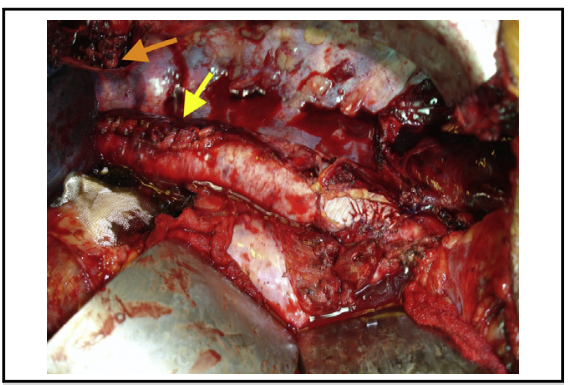

Demonstration of aneurysm sac closure and complete rib resection during TAAA repair.

CENTRAL MESSAGE

Open thoracoabdominal aortic aneurysm repair remains a technical challenge. The current report reminds us that even seemingly minor surgical details can have major consequences on patient outcomes.

and aneurysm sac calcification, among other etiologies. Previous ex vivo mechanical analyses mimicking friction injury have demonstrated the potential for graft rupture in the first 15 to 20 days postoperatively. ${ }^{7}$

This report reinforces the meticulous anatomic and physiologic detail necessary for safe repair of open TAAA. At our institution, we use a strict algorithm to protect the TAAA repair graft not only from mechanical injury, but also from adhesions to the lung and potential sources of infection. First, as the authors reference in this report, the remnant aneurysm sac should always, to the greatest extent possible, be closed around the entire length of the Dacron graft (Figure 1). Second, we prefer to "shingle" or divide the rib (usually the fifth if distal arch exposure is required and the sixth or seventh if the aneurysm does not extend to the distal arch/proximal descending thoracic aorta) posteriorly approximately 2 to $3 \mathrm{~cm}$ from its insertion into the spinal column. We then completely resect the stump of the divided rib posteriorly flush with the transverse process of the associated vertebra using a box cutting instrument designed for this purpose (Figure 1). This technique leaves no residual rib stump and has proven sufficient to protect the graft in our experience. However, if exposed graft remains a concern, a number of autologous flaps, including omental and rectus abdominus, have been used to prevent graft infection in the context of mycotic 


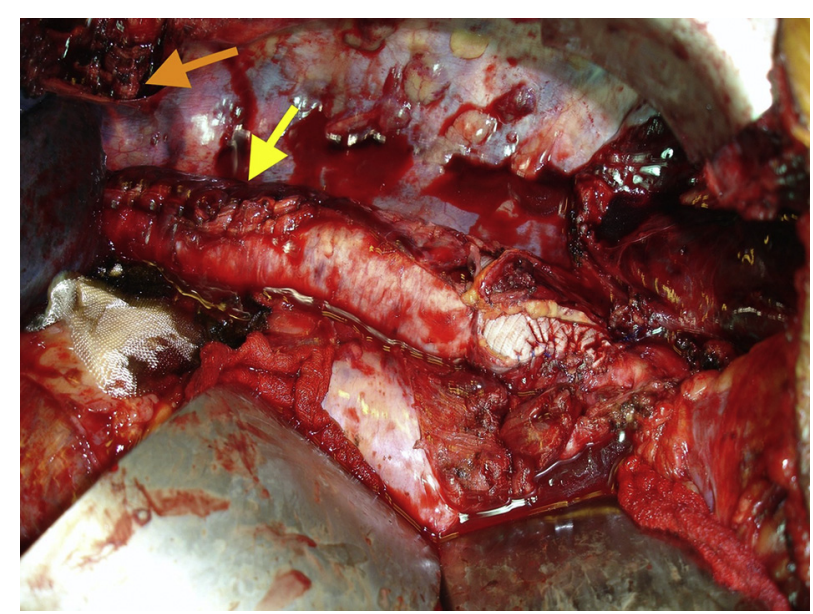

FIGURE 1. Intraoperative photograph of a completed open extent I thoracoabdominal aortic aneurysm repair showing the aneurysm sac completely closed around the length of the graft (yellow arrow). The orange arrow denotes where the stump of the divided fifth rib has been resected flush with the vertebral body such that no rib stump remains.

$\mathrm{TAAA}^{8}$ and could serve as an aggressive measure in noninfectious scenarios, although we have not found this to be necessary in our experience. ${ }^{9}$

In summary, Ishii and colleagues remind us that we must remain vigilant in the care of these complex patients, and that attention to even seemingly minor details is essential to avoid "black swan" events such as the one described in this report.

\section{References}

1. Polanco AR, D'Angelo AM, Shea NJ, Allen P, Takayama H, Patel VI. Increased hospital volume is associated with reduced mortality after thoracoabdominal aortic aneurysm repair. J Vasc Surg. 2021;73:451-8.

2. Pipinos II, Reddy DJ. Secondary aortoesophageal fistula. J Vasc Surg. 1997;26: 144-9.

3. Castillo Barbosa A, Pérez Rivera CJ, Tellez LJ, Cabrera Rivera P, GonzálezOrozco A, Mosquera Paz M. Left diaphragmatic hernia following thoracoabdominal aortic repair: a case report. Int J Surg Case Rep. 2020;70:209-12.

4. Coselli JS, de la Cruz KI, Preventza O, LeMaire SA, Weldon SA. Extent II thoracoabdominal aortic aneurysm repair: how I do it. Semin Thorac Cardiovasc Surg. 2016;28:221-37.

5. Tshomba Y, Bertoglio L, Marone EM, Psacharopulo D, Iob G, Chiesa R. Graft perforation by a dislocated rib fracture after open thoracoabdominal aortic repair: emergent endovascular and open repair. J Endovasc Ther. 2010;17:126-30.

6. Ishii T, Iguchi Y, Tsukada T, Osaka M. Aortic graft perforation by a rib stump after thoracic aorta replacement: a case report and literature review. J Thorac Cardiovasc Surg Tech. 2021;8:40-2.

7. Tanaka H, Okada K, Yamashita T, Kawanishi Y, Matsumori M, Okita Y. Disruption of the vascular prosthesis caused by aortic calcification after replacement of the thoracoabdominal aortic aneurysm. Ann Thorac Surg. 2006;82:1097-9.

8. Kuniyoshi Y, Koja K, Miyagi K, Uezu T, Yamashiro S, Arakaki K. Graft for mycotic thoracic aortic aneurysm: omental wrapping to prevent infection. Asian Cardiovasc Thorac Ann. 2005;13:11-6.

9. Benrashid E, Wang H, Andersen ND, Keenan JE, McCann RL, Hughes GC. Complementary roles of open and hybrid approaches to thoracoabdominal aortic aneurysm repair. J Vasc Surg. 2016;64:1228-38. 